\title{
Effects of coating spherical iron oxide nanoparticles
}

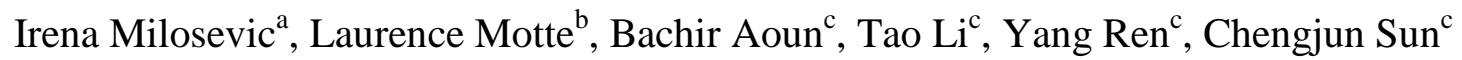
and Marie-Louise Saboungi,

${ }^{\mathrm{a}}$ Powder Technology Laboratory, Ecole Polytechnique Federale de Lausanne (EPFL), CH-1015 Lausanne, Switzerland

${ }^{\mathrm{b}}$ Inserm, U1148, Laboratory for Vascular Translational Science, UFR SMBH, Université Paris 13, Sorbonne Paris Cité, F-93017 Bobigny, France

${ }^{\mathrm{c}}$ Advanced Photon Source, Argonne National Laboratory, Argonne, IL 60439, USA

${ }^{\mathrm{d}}$ IMPMC- UPMC, UMR CNRS 7590, 4 Place Jussieu, F-75005 Paris, France \& University of Orleans, Orleans, France

${ }^{\mathrm{e}}$ BCMaterials, Edificio No. 500, Parque Tecnológico de Vizcaya, 48160 Derio, Spain

${ }^{\mathrm{d}}$ Corresponding author, ml.saboungi@gmail.com

\begin{abstract}
We investigate the effect of several coatings applied in biomedical applications to iron oxide nanoparticles on the size, structure and composition of the particles. The four structural techniques employed - TEM, DLS, VSM, SAXS and EXAFS - show no significant effects of the coatings on the spherical shape of the bare nanoparticles, the average sizes or the local order around the Fe atoms. The NPs coated with hydroxylmethylene bisphosphonate or catechol have a lower proportion of magnetite than the bare and citrated ones, raising the question whether the former are responsible for increasing the valence state of the oxide on the NP surfaces and lowering the overall proportion of magnetite in the particles. VSM measurements show that these two coatings lead to a slightly higher saturation magnetization than the citrate.
\end{abstract}




\section{Keywords: Magnetic nanoparticle, coating, valence state, synchrotron x-ray}

\section{Background}

Magnetic nanoparticles (MNPs) are being exploited for applications in biomedicine, due to their many favourable properties (Pankhurst et al., 2003). The synthesis of iron oxide nanoparticles is now quite routine, with sizes ranging from $\sim 1$ to $\sim 100 \mathrm{~nm}$, comparable to the dimensions of cells (10-100 $\mu \mathrm{m})$, viruses (20-450 nm) and proteins (5-50 nm), allowing them to get close to a biological entity of interest. In the last decade, MNPs have been coated with various molecules ensuring their stability and biocompatibility with their applications in vivo. These assemblies are amenable to manipulation by an external magnetic field gradient to deliver a package such as a drug, fluorescent labels or radionuclide atoms to a targeted region of the body. A time-varying magnetic field could be used to heat them and transforming them into hyperthermia agents, delivering toxic amounts of thermal energy to targeted bodies such as tumours or as chemotherapy and radiotherapy enhancement agents, where tissue warming results in more effective malignant cell destruction (Shkilnyy et al. 2010).

For most of these applications, it is important that the particles have a single magnetic domain, requiring dimensions less that the domain wall thickness, typically $70 \mathrm{~nm}$ for the iron oxide (IO) particles studied here, and be coated with specific ligands for the biomedical application of interest. The size distribution affects the function of iron oxide nanoparticles in many biomedical applications including diagnostics (de Montferrand et al., 2013), hyperthermia (Fortin et al., 2007) and MRI (Huang et al., 2010; Jung et al., 2014). The question then arises as to what extent these coatings affect the size, structure, composition and valence distribution, and hence the magnetic properties, of the host nanoparticles.

In the present paper we address this issue for IO NPs, the most widely used NPs in biomedicine, and investigate the effect of coatings applied in our previous work, referenced below, on the size, structure, and composition of the particles. Various techniques yield different estimates of size distributions and we use three methods transmission electron microscopy (TEM), dynamic light scattering (DLS) and smallangle x-ray scattering (SAXS) to determine what effects if any the coatings have on the size distribution. IO NPs are normally composed of a mixture of magnetite $\left(\mathrm{Fe}_{3} \mathrm{O}_{4}\right)$ and maghemite $\left(\gamma-\mathrm{Fe}_{2} \mathrm{O}_{3}\right)$. These compounds are difficult to distinguish by conventional 
diffraction and therefore we use X-ray absorption near-edge (XANES) and far-edge (EXAFS) spectroscopy to determine the effects of coating on the valence distribution and local structure around the Fe atoms. We also use vibrating sample magnetometry (VSM) to determine the magnetic properties.

\section{Methods}

2.1 Nanoparticle synthesis. Spherical iron oxide (IO) NPs were prepared by coprecipitation (Milosevic et al., 2014) by addition $\left(0.0144 \mathrm{~mol} . \mathrm{min}^{-1}\right)$ of an ammonium hydroxide solution $\left(0.36 \mathrm{~mol} . \mathrm{L}^{-1}\right)$ to an iron chloride solution $\left([\mathrm{Fe}]=0.12 \mathrm{~mol} . \mathrm{L}^{-1}\right.$ with a stoichiometric ratio $\mathrm{Fe}(\mathrm{II}) / \mathrm{Fe}(\mathrm{III})=1 / 2)$. The entire process was maintained at $30^{\circ} \mathrm{C}$. The bare NPs were washed several times by magnetic decantation and redispersed in water at $\mathrm{pH}=2$ using ultrasound in order to obtained a stable ferrofluid of bare nanoparticles.

2.2 Nanoparticle surface functionalization. The NPs were coated with hydroxylmethylene bisphosphonate (Bolley et al., 2013a; Lalatonne et al., 2008; Motte et al., 2011), catechol (Richard et al., 2015; Bolley et al., 2013b; Guénin et al , 2014) and citrate (Lalatonne et al., 2014) with methods previously described. For the hydroxylmethylene bisphosphonate (HMBP: pKa= 0.8, 2.2, 6.3, 10.9 for P-OH/P-O- and 4.8 for $\mathrm{COOH} / \mathrm{COO}-)$ coating, $10 \mathrm{~mL}$ of an aqueous $\mathrm{HMBP}$ solution $\left(15 \mathrm{mg} \mathrm{mL}^{-1}\right)$ at $\mathrm{pH}$ 2 was directly mixed with $10 \mathrm{~mL}$ of bare IO nanoparticle suspension $\left(6 \mathrm{mg} \mathrm{mL}^{-1}\right)$ at $\mathrm{pH}$ 2. After $2 \mathrm{~h}$ at room temperature, the excess HMBP was removed from the coated particles using a magnet at $\mathrm{pH}$ 2. The coated NPs were dispersed in distilled water and adjusted to $\mathrm{pH} 7$.

For the catechol (CA: $\mathrm{pKa}=8.6,11.5$ cathecol functions and 4.4 for $\mathrm{COOH} / \mathrm{COO}-$ ) coating, the NP surfaces were directly functionalized with caffeic acid: $10 \mathrm{~mL}$ of aqueous caffeic acid solution $\left(10 \mathrm{mg} \mathrm{mL}^{-1}\right)$ at $\mathrm{pH} 10$ were mixed with $10 \mathrm{~mL}$ of bare $\mathrm{NP}$ suspension $\left(6 \mathrm{mg} \mathrm{mL}^{-1}\right)$ at $\mathrm{pH} 10$. After mixing for $2 \mathrm{~h}$ at room temperature, the functionalized NPs were washed five times by magnetic separation at $\mathrm{pH} 2$. The coated NPs were dispersed in distilled water and adjusted to $\mathrm{pH} 7$.

For the citrate ( $\mathrm{Cit}: \mathrm{pKa}=5.2,4.3$ et 2,9 for $\mathrm{COOH} / \mathrm{COO}-$ ) ( coating, the NP surfaces were functionalized with citrate ions: $10 \mathrm{~mL}$ of aqueous sodium citrate solution $\left(20 \mathrm{mg} \mathrm{mL}^{-1}\right)$ at $\mathrm{pH} 2$ were mixed with $10 \mathrm{~mL}$ of bare $\mathrm{NP}$ suspension $\left(10 \mathrm{mg} \mathrm{mL}^{-1}\right)$ at $\mathrm{pH} 2$. After sonicating for 10 minutes at room temperature and additional mixing for $2 \mathrm{~h}$, the functionalized NP were washed five times by magnetic separation at $\mathrm{pH} 2$. The coated NPs were dispersed in distilled water and adjusted to $\mathrm{pH} 7$. 
2.3 TEM. Bright-field imaging and electron diffraction studies were carried out with a Philips FEI CM10 microscope operating at $200 \mathrm{kV}$. The samples were prepared by deposition on a carbon film supported by a copper grid placed on a filter paper. Average particle diameters were obtained by fitting the diameter distribution with a log-normal function.

2.4 DLS. The hydrodynamic diameter and the zeta potential of nanoparticles were determined with a Nano-ZS ZEN 3600 device (Malvern Instruments, Malvern, UK).

2.5 VSM. A vibrating sample magnetometer (VSM, Quantum Design, Versalab) was used for magnetic characterization. VSM measures the magnetization $M$ by cycling the applied field $H$ from -30 to $+30 \mathrm{kOe}$ with a step rate of 100 Oe. $\mathrm{s}^{-1}$ for two times. Measurements of $M(H)$ were performed on liquid samples at $50 \mathrm{~K}$. ZFC curves were obtained by first cooling the system in zero field from 300 to $50 \mathrm{~K}$ and then a $100-\mathrm{Oe}$ field was applied and $M(H)$ recorded while gradually increasing the temperature. The FC curves were measured by decreasing the temperature in the same applied field.

2.6 SAXS. The scattering intensity $I(Q)$ was measured as a function of scattering vector $Q(=4 \pi \sin \theta / \lambda$, where $\theta$ is the Bragg angle and $\lambda$ the wavelength $)$ and analysed with a spherical model fit:

$$
I(Q)=\frac{4}{Q^{3}}|\quad|^{2}\left|\sin \left(\frac{Q d}{2}\right) \frac{Q d}{2} \cos \left(\frac{Q d}{2}\right)\right|^{2},
$$

where $d$ is the diameter of the particle and $\Delta \rho$ is the electron density difference between the particle and the medium. The average particle size was calculated from the diameter distribution function $D(d)$.

2.7 XANES and EXAFS. Experiments were performed at the 20-BM-B beamline at the Advanced Photon Source at Argonne National Laboratory. These are sensitive to the electronic structures and local geometries of the absorbing atoms in a sample, so that changes in the oxidation state and coordination geometry of the iron atoms on decreasing the particle size and the interactions with molecules adsorbed on the NP surface can in principle be extracted. (Iwasawa, 1996; Chen et al., 2002). In particular, the presence of FeII in $\mathrm{Fe}_{3} \mathrm{O}_{4}$ and only FeIII in $\gamma-\mathrm{Fe}_{2} \mathrm{O}_{3}$ can be discriminated (Auffan et al., 2008). The ratios of the different $\mathrm{Fe}$ oxide phases present in the nanoparticles were determined by fitting the XANES spectrum to a linear combination of iron oxide phases with the Athena software package (Ravel and Newville, 2005). 


\section{Results}

3.1 TEM. The TEM images and electron diffraction patterns showed well-crystallized NPs (Fig. 1). These can be either magnetite or maghemite NP, or a combination of the two, since these phases cannot be distinguished by electron diffraction. The coating did not change the shape or the size of the particles. Fig. 1B shows a typical distribution of particle diameters, corresponding to a mean diameter $d_{\mathrm{av}}=7 \mathrm{~nm}$ with a distribution between 4 and $16 \mathrm{~nm}$.

A

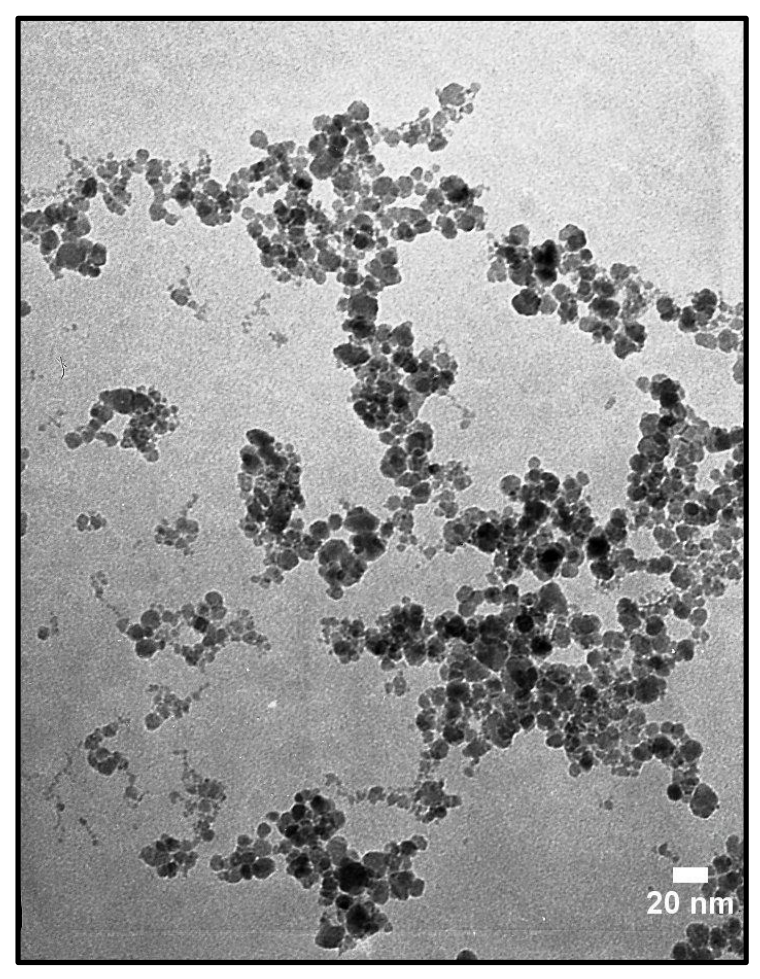

B

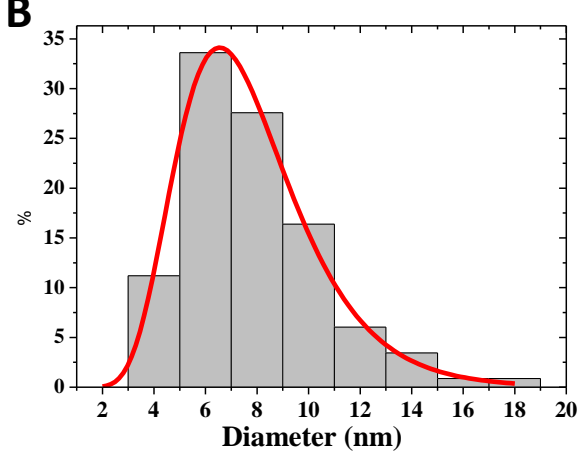

C

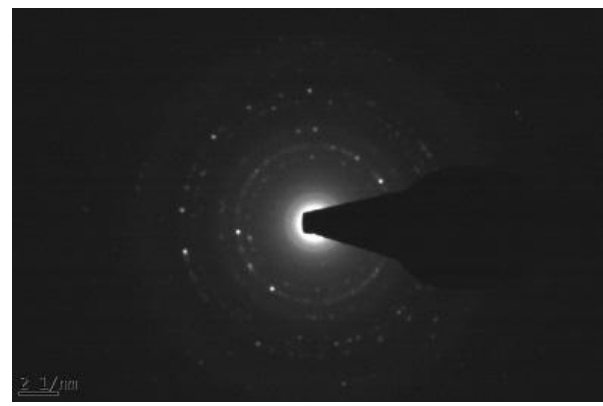

Fig. 1: (A) TEM micrograph, (B) distribution of particle diameters $d$ and (C) electron diffraction patterns of an assembly of bare IO NPs.

3.2 FTIR. To elucidate the interactions between the NP surfaces and the HMBP, CA and Cit ligands, we performed FTIR spectroscopic measurements. 


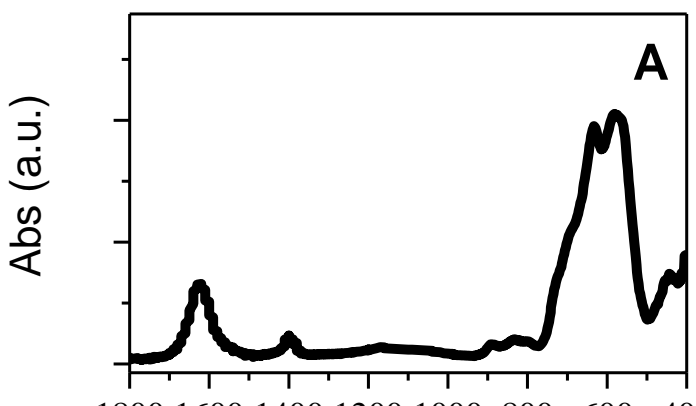

18001600140012001000800600400

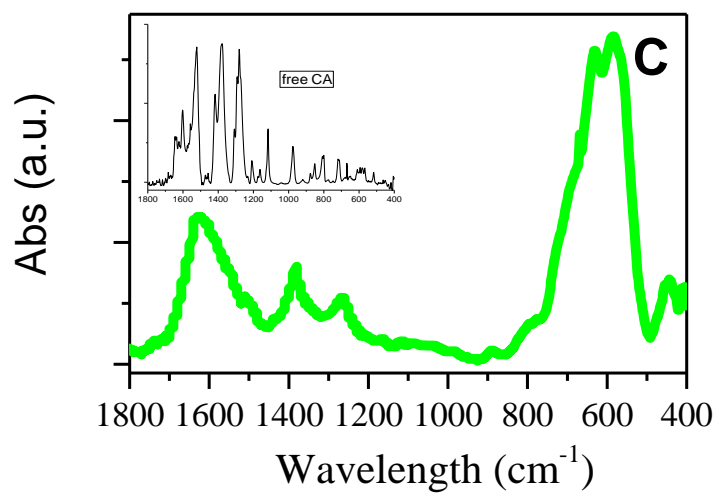

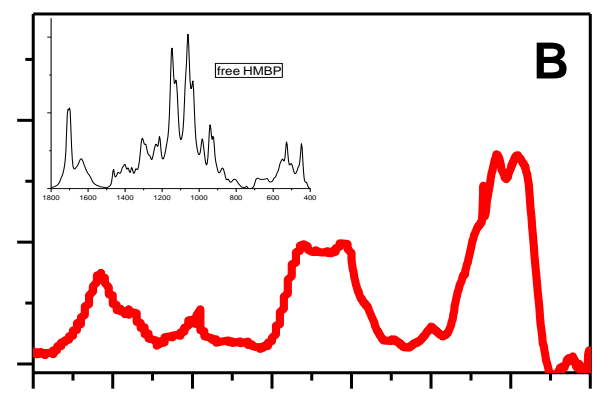
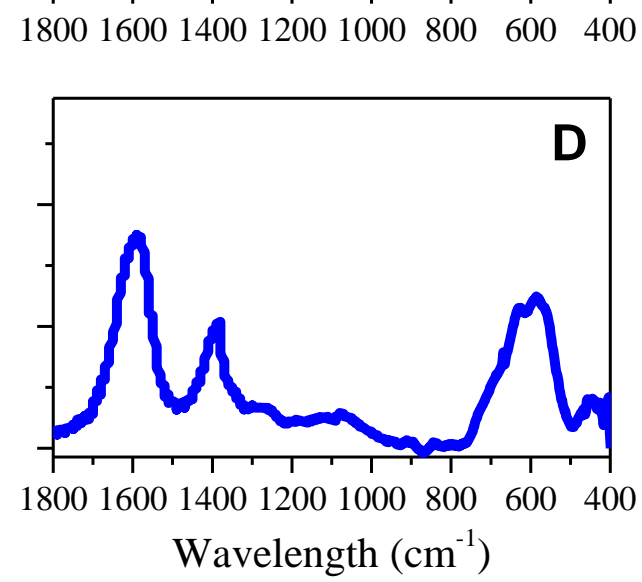

Fig. 2: FTIR spectra (absorption vs. wavelength) for 7 nm (A) bare IO, (B) IO@ HMBP, (C) IO@CA and (D) IO@Cit NPs. The insets in B and C show the spectra of the free molecules.

Figure 2A shows a characteristic FTIR spectrum of bare IO NPs with a strong Fe-O stretching vibration band of the spinel phase at 585 and $635 \mathrm{~cm}^{-1}$. The bands in this region also suggest the IR features of maghemite crystallites (Tartaj et al., 2003). The band at $620 \mathrm{~cm}^{-1}$ is assigned to hydroxide and water physisorbed on the IO surface (Belin et al., 2004). In addition to the bands of the bare IO NPs, the coated NPs have some specific features. The spectrum of IO@HMBP NPs, Fig. 2B, shows the bands of phosphonic vibrations between 900 and $1200 \mathrm{~cm}^{-1}$, indicating the linkage of the bisphosphonic moiety to the surface of the IO (Lalatonne et al., 2008, Guénin et al., 2012, Benyettou et al., 2009; 2011, Guénin et al., 2014). Stronger characteristic vibration bands in the carboxylate region (1700-1400 $\mathrm{cm}^{-1}$ ) are observed due to grafting of the molecule to the surface. In Fig. 2C, the spectrum of IO@CA NPs shows a strong characteristic band between 1650 and $1600 \mathrm{~cm}^{-1}$, in accordance with previous observations (Guénin 2014 et al.,, Bolley et al., 2013b). This band is attributed to the asymmetric $v(\mathrm{C}=\mathrm{O})$ stretching vibration of the carboxylate function coupled with the $v(\mathrm{C}=\mathrm{C})$ vibration of the alkene function, which is related to the formation of a coordinate 
bond between the NP surface and the catecholic aromatic ring (Shultz et al., 2007, Bolley et al., 2013b). The vibration bands corresponding to $\mathrm{C}=\mathrm{C}$ stretching between 1550 and $1650 \mathrm{~cm}^{-1}$ as well as vibration bands corresponding to $\mathrm{C}-\mathrm{O}$ stretching and bending (between 950 and $1300 \mathrm{~cm}^{-1}$ ) appear to be changed due to the surface modification, compared with the spectrum of free molecules shown in the inset.. The IO@Cit spectrum in Fig 2D shows some modifications in the carboxylate region attributable to the $\mathrm{C}=\mathrm{O}$ vibration from the citrate $\mathrm{COOH}$ group characterized by a shift from $1625 \mathrm{~cm}^{-1}$ in the free citrate to $1600 \mathrm{~cm}^{-1}$ in the complexed IO@Cit. This shift can be attributed to the binding of citrate ions to the IO surface by chemisorption of their carboxylate group (Cheraghipour et al., 2012).

3.3 DLS. Results for the bare IO NP and coated nanoparticles are shown in Figs. 3 and 4, respectively. The colloidal behaviour - hydrodynamic diameter and surface charge - was determined by DLS in water for bare IO NPs and for coated NPs from $\mathrm{pH} 2$ to 12. This technique gives an indication of surface charge on a particulate species, which plays an important role in determining colloidal stability and susceptibility to aggregation and precipitation problems, as well as protein and cellular surface binding in vivo. The isoelectric point (IEP) of bare IO NP is around $\mathrm{pH} 7$ and they precipitate at physiological $\mathrm{pH}$, being positively and negatively charged at acid and basic $\mathrm{pH}$, respectively (Fig. 3). 


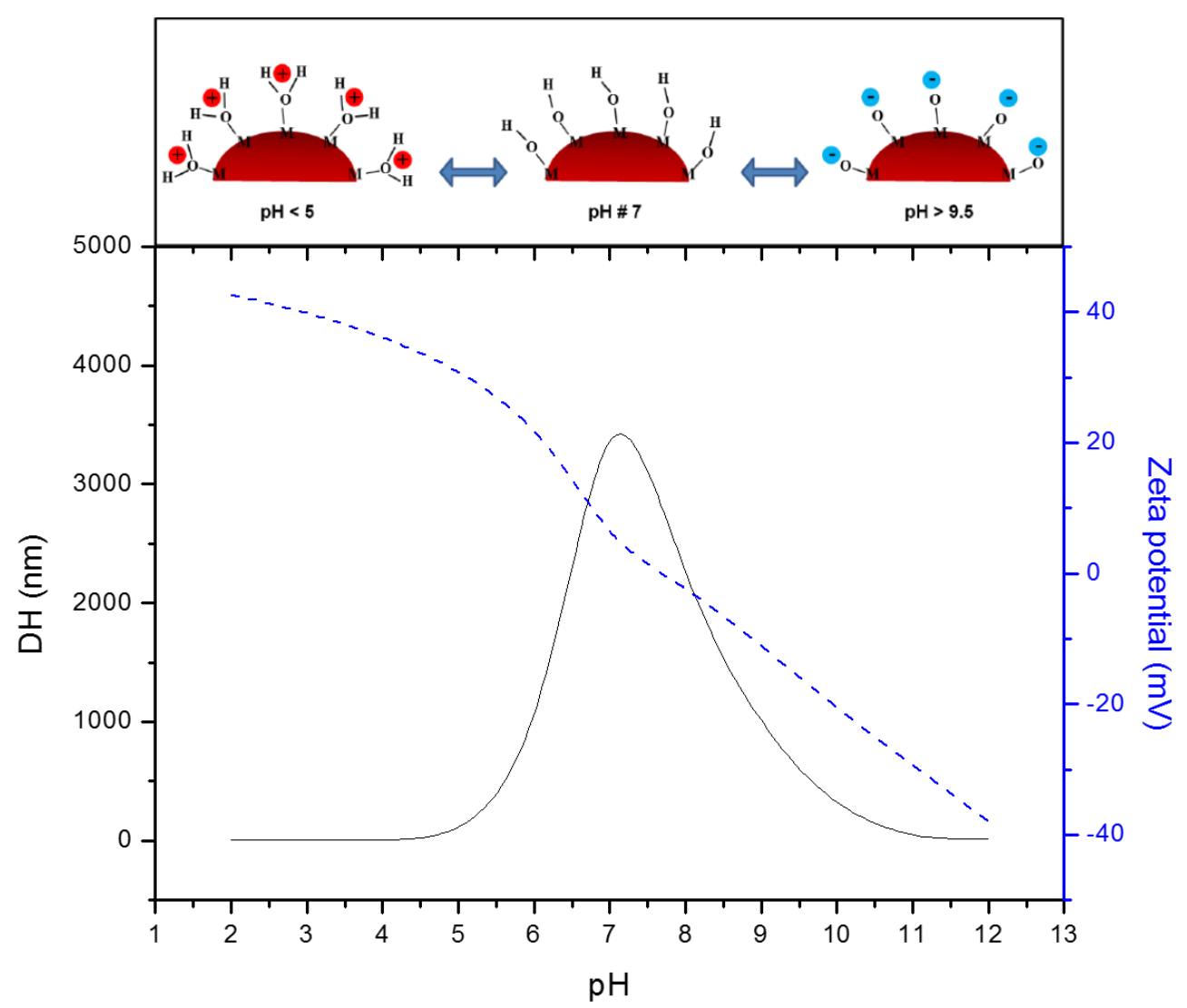

Fig. 3. Top: Charge distributions on bare NPs as a function of $\mathrm{pH}$. Bottom: hydrodynamic diameter (DH) and zeta potential as a function of $\mathrm{pH}$ for bare NPs.

Figure 4 shows the evolution of hydrodynamic diameter and surface charge versus $\mathrm{pH}$ for the various coatings. The NPs form a highly stable ferrofluid at $\mathrm{pH}$ between 4 to 11 . The zeta potential at physiological $\mathrm{pH}$ is negative for the coated NPs, indicating the efficiency of the coating. The zeta potential at physiological $\mathrm{pH}$ is negative for the coated NPs, indicating the efficiency of the coating. The negative charges of the coated NPs are due to the presence of carboxylate end functions. The coatings showed no significant effects on the hydrodynamic diameter. 


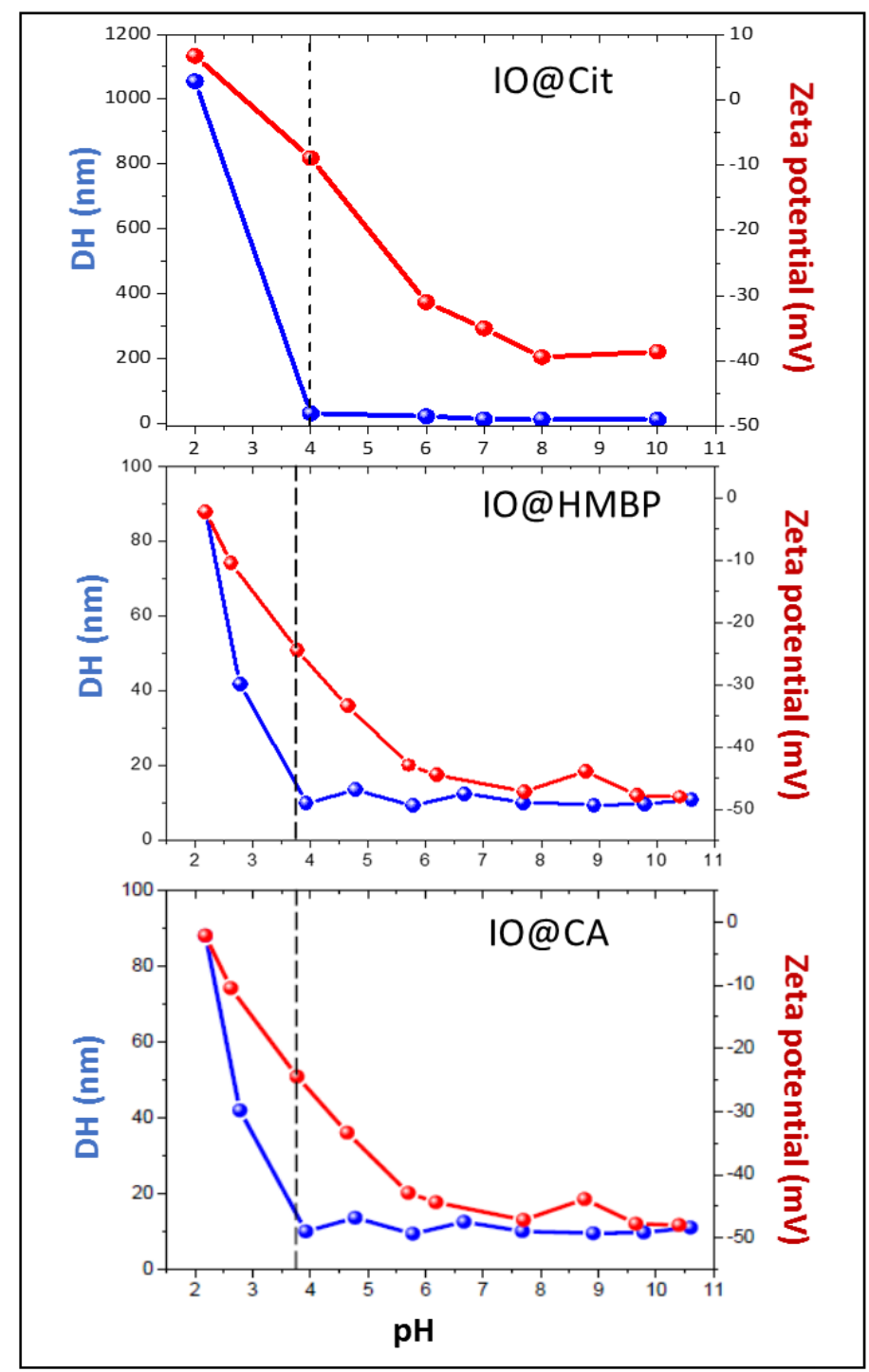

Fig 4. Hydrodynamic diameter (DH) and zeta potential for the various coatings as a function of $\mathrm{pH}$.
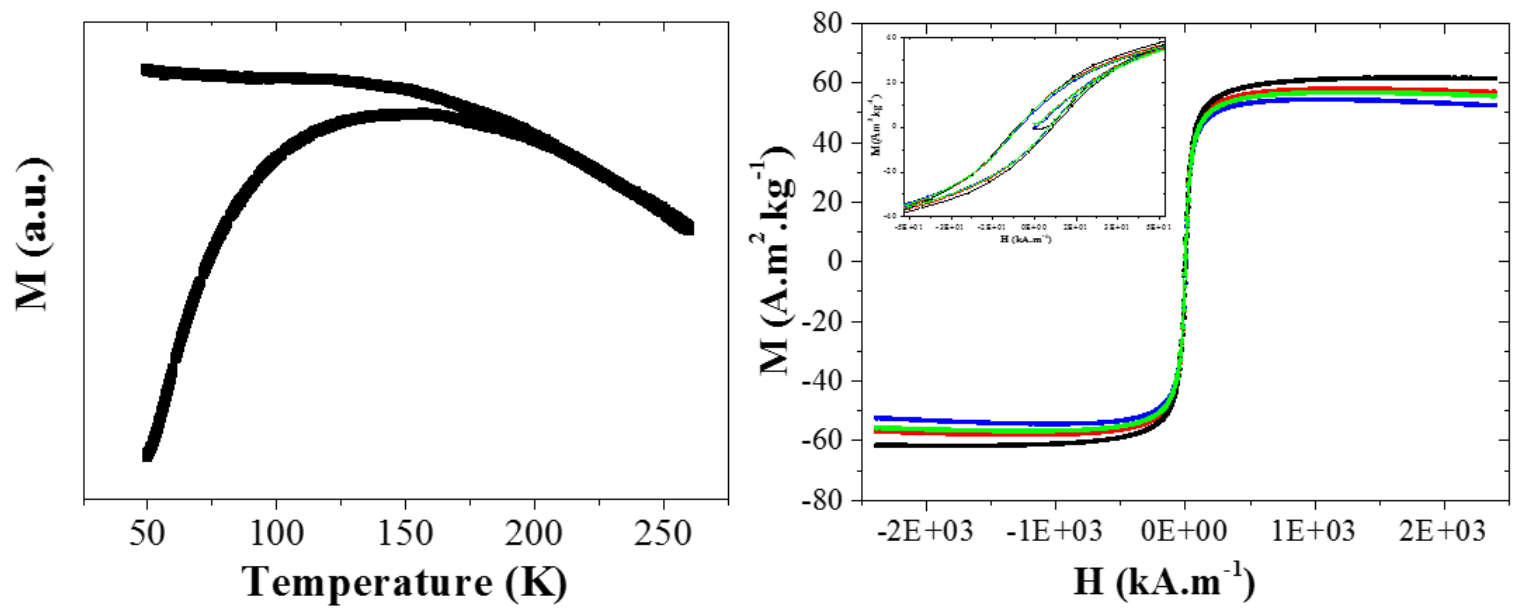
Fig. 5. Left: ZFC (lower) and FC (upper) magnetization curves of bare IO NPs. Right: Magnetization curves measured at 50K for bare IO NPs (black) and IO@HMBP (red), IO@CA (green) and IO@Cit (blue) coated NPs. The inset shows an enlarged view of the hysteresis loops at $50 \mathrm{~K}$.

3.4 VSM. Figure 5 (left) shows the ZFC and FC $M(T)$ curves measured at 100 Oe for bare IO NPs. In the ZFC curve the magnetization increases gradually up to the blocking temperature of $150 \mathrm{~K}$ and then a $1 / T$ Curie-type decrease is observed. Thus, the NPs are superparamagnetic at room temperature. Figure 5 (right) shows the hysteresis curve for $M(H)$ at $50 \mathrm{~K}$ for the bare and coated IO NPs. No significant effects appear in the coercivity field due to surface modification (see inset). Nevertheless, we observe a decrease of the saturation magnetization related to the different coatings, with NPs coated with stronger coordination ligands (bisphosphonate and catechol) showing a slightly higher saturation magnetisation of approximately $58 \mathrm{~A} \cdot \mathrm{m}^{2} \cdot \mathrm{kg}^{-1}$ compared with those stabilized by citrate ions $\left(54 \mathrm{~A} \cdot \mathrm{m}^{2} \cdot \mathrm{kg}^{-1}\right)$.

These values are lower than the theoretical value of bulk magnetite $\left(92 \mathrm{emu} \mathrm{g}^{-1}\right)$ even for the bare IO NPs $\left(61 \mathrm{~A} \cdot \mathrm{m}^{2} \cdot \mathrm{kg}^{-1}\right)$. It is usually attributed to surface effects: spin canting, surface disorder and/or adsorbed species (Daou et al., 2006).

3.5 SAXS. Typical plots of scattering intensity $I(Q)$ for the bare NPs and the corresponding distribution of diameters $D(d)$ obtained from fits of Eq. (1) are shown in Fig. 6. The goodness of fits with Eq. (1) indicated so significant deviation from spherical shape. A bimodal distribution was observed in each sample, with one diameter smaller than $2 \mathrm{~nm}$ and another around $12 \mathrm{~nm}$. The average diameter was found to be $11 \mathrm{~nm}$ in every case. The particle size obtained using SAXS analysis was thus larger than that observed by TEM. This is not unusual and results from the different weightings in the two techniques. 

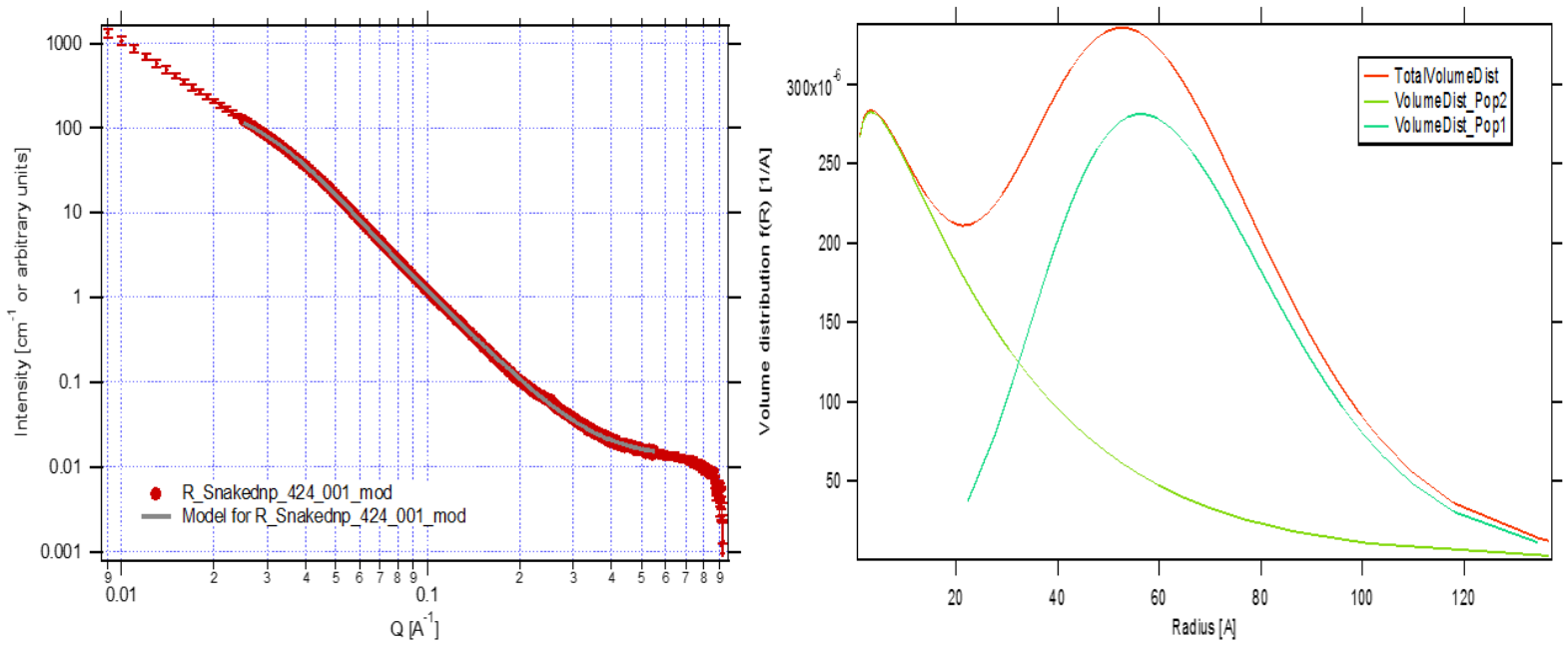

Fig. 6. (Left) SAXS intensity $I(Q)$ and (right) the corresponding distribution of diameters $D(d)$ for the bare NPs

3.6 XANES and EXAFS. Spectra for the bare and coated nanoparticles are shown in Fig. 7, and the magnetite - maghemite proportions obtained by XANES with linear combination fits of model spectra are given in Table 1.
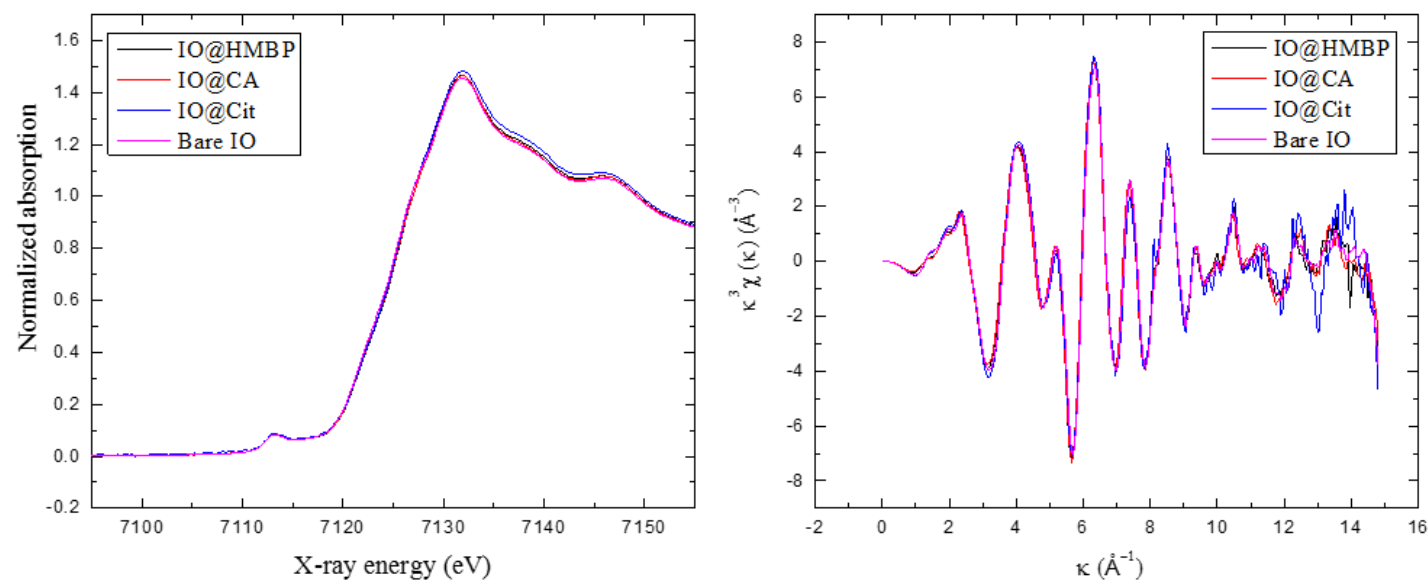

Fig. 7. (Left) XANES and (right) EXAFS spectra for bare and coated nanoparticles.

The BP- and CS-coated NPs have less magnetite than the bare and citrated ones. The fact that bisphosphonate and catechol are strong chelators, with strong affinity for iron, raises the question whether these are responsible for increasing the valence state of the oxide on 
the NP surfaces, and/or enlarging the maghemite shell, and hence lowering the overall proportion of magnetite in the particles.

Table 1. Magnetite $\left(\mathrm{Fe}_{3} \mathrm{O}_{4}\right) /$ maghemite $\left(\gamma-\mathrm{Fe}_{2} \mathrm{O}_{3}\right)$ proportions obtained by XANES with linear combination fitting.

\begin{tabular}{|l|l|l|l|}
\hline & $\mathrm{Fe}_{3} \mathrm{O}_{4}$ & $\gamma-\mathrm{Fe}_{2} \mathrm{O}_{3}$ & $\mathrm{R}$ factor \\
\hline Bare IO NP & $0.29 \pm 0.01$ & 0.71 & $3.10^{-4}$ \\
\hline IO@Cit & $0.275 \pm 0.02$ & 0.725 & $1.10^{-3}$ \\
\hline IO@ HMBP & $0.225 \pm 0.02$ & 0.775 & $6.10^{-4}$ \\
\hline IO@CA & $0.23 \pm 0.01$ & 0.77 & $4.10^{-4}$ \\
\hline
\end{tabular}

A recent study of hollow NPs (Khursid et al., 2015) also showed a high proportion (0.82) of maghemite.

The local order around the Fe atoms probed by the EXAFS measurement appeared generally similar in the bare and coated NPs, with some slight differences at high $k$ for the citrate-coated particles.

\section{Conclusions}

The four structural techniques employed - TEM, DLS, SAXS and EXAFS - show no significant effects of the coatings on the spherical shape of the bare nanoparticles, the average sizes or the local order around the Fe atoms. Diameters derived from SAXS are slightly higher than those from TEM, a not uncommon result, and the hydrodynamic diameters obtained from DLS appreciably higher as expected.

One unexpected result from the XANES measurements is that the NPs coated with hydroxylmethylene bisphosphonate or catechol have a lower proportion of magnetite than the bare and citrated ones. The fact that these are strong chelators, with strong affinity for iron, raises the question whether they are responsible for increasing the valence state of the oxide on the NP surfaces and lowering the overall proportion of magnetite in the particles. Also, the VSM studies show that these two coatings lead to a slightly higher saturation magnetization than the citrate. 
As a guide to future work, these results demonstrate that X-ray synchrotron techniques can provide a rapid and definitive determination of size, shape, structure, composition and valence distribution of magnetic nanoparticles.

\section{Acknowledgements}

Use of the Advanced Photon Source, an Office of Science User Facility operated for the DOE Office of Science by Argonne National Laboratory, was supported by the DOE under Contract No. DE-AC02-06CH11357. MLS acknowledges funding from the Spanish Ministry of Economy and Competitiveness (grant MAT2013-48366-C2-1)

\section{References}

M. Auffan, W. Achouak, J. Rose, M.-A. Roncato, C. Chanéac, D. T. Waite, A. Masion,

C. Woicik, M. R. Wiesner' J.-Y. Bottero, Environ. Sci. Technol., 2008, 42, 6730-5

T. Belin, N. Millot, F. Villiéras, O. Bertrand, J. P. Bellat, J. Phys. Chem. B, 2004, 108, 5333-5340.

F. Benyettou, Y. Lalatonne, O. Sainte-Catherine, M. Monteil, L. Motte. Int. J.

Pharmaceutics, 2009, 379, 324-327.

F. Benyettou, E. Guenin, Y. Lalatonne, L. Motte, Nanotechnology, 2011, 22, 055102.

J. Bolley, E. Guénin, N. Lievre, M. Lecouvey, M. Soussan, Y. Lalatonne and L. Motte, Langmuir, 2013a, 29, 14639-14647.

J. Bolley, Y. Lalatonne, O. Haddad, D. Letourneur, M. Soussan, J. Perard-Viret, L. Motte, Nanoscale, 2013b, 5, 11478-89.

L. X. Chen, T. Li, M. C. Thurnauer, R. Csencsits, T. Rajh, J. Phys. Chem. B, 2002, 106, 8539-8546.

E. Cheraghipour, S. Javadpour, A. R. Mehdizadeh, J. Biomed. Sci. Eng., 2012, 5, 715

T. J. Daou, G. Pourroy, S. Bégin-Colin, J. M. Grenèche, C. Ulhaq-Bouillet, P. Legaré, P. Bernhardt , C. Leuvrey , G. Rogez, Chem. Mater., 2006, 18, 4399-4404.

J. P. Fortin, C. Wilhelm, J. Servais, C. Menager, J-C Bacri, F. Gazeau, J. Am. Chem. Soc., 2007, 129 (9), pp 2628-2635.

E. Guénin, J. Hardouin, Y. Lalatonne, L. Motte, J Nanopart. Res., 2012, 14, 965-975.

E. Guénin, Y. Lalatonne, J. Boley, I. Milosevic, C. Platas-Iglesias,L. Motte, J. Nanopart. Res., 2014, 16, 2596-2616 
J. Huang, L. Bu, J. Xie, K. Chen, Z. Cheng, X. Li, and X. Chen, ACS Nano, 2010, 4 (12), 71517160

Y. Iwasawa, Y., Ed., X-ray Absorption Fine Structure for Catalysts and Surfaces, Ser. Synchrotron Radiat. Technol. Appl., 1996, vol. 2.

H. Jung, B. Park, C. Lee, J. Cho, J. Suh, J. Y. Park, Y Kim, J. Kim, G. Cho, H. J. Cho, Nanomedicine, 2014 Nov; 10 (8), 1679-89.

H. Khursid, P. Lampen-Kelley, O. Iglesias, J. Alonso, M.-H. Phan, C.-J. Sun, M.-L. Saboungi, H. Srikanth, Sci. Rep., 2015, 5, 15054.

Y. Lalatonne, C. Paris, J .M. Serfatty, P. Weinmann, M. Lecouvey, and L. Motte, Chem. Commun., 2008, 2553-2555.

Y. Lalatonne, L. Motte, V. Russier, A.T. Ngo, P. Bonville and M.P. Pileni, J. Phys. Chem B, 2004, 108, 1848.

I. Milosevic, F. Warmont, Y. Lalatonne and L. Motte, 2014, RSC Adv., 4, 49086.

I. Milosevic, S. Guillot, M. Tadic, E. Duguet, L. Forro, M.-L. Saboungi, 2014, Applied Physics Letters, 104, 43701

C. de Montferrand, L. Hu, I. Milosevic, et al Acta Biomaterialia, 2013, 9(4), 61506157.

L. Motte, F. Benyettou, C. de Beaucorps, M. Lecouvey, I. Milosevic, Y. Lalatonne, Faraday Disc., 2011, 149, 211-225

Q. A. Pankhurst, J. Connolly, S. K. Jones, J. Dobson, J. Phys. D: Appl. Phys., 2003, 36, R167-R181.

B. Ravel and M. Newville, J. Synchrotron Radiat., 2005, 12, 537-541.

S. Richard, M. Boucher, A. Herbet, Y. Lalatonne, S. Meriaux, D. Boquet and L. Motte, J. Mater. Chem. B, 2015, 3, 2939-2942.

M. D. Shultz, J. U. Reveles, S. N. Khanna, E. E. Carpenter, J. Amer. Chem. Soc., 2007, $129,2482-2487$.

A. Shkilnyy, E. Munnier, K. Herve, et al. J. Phys. Chem. C, 2010, 114, 13 5850-5858

M. Tadic, I. Milosevic, S. Kralj, M.-L. Saboungi, and L. Motte, Applied Physics Letters 106, 183706, 2015

P. Tartaj, M. del Puerto Morales, S. Veintemillas-Verdaguer, T. Gonzalez-Carreno, C. J. Serna, J. Phys. D: Appl. Phys., 2003, 36, R182-R197 